\title{
Sarcomatous Change After Sellar Irradiation in a Growth Hormone- Secreting Pituitary Adenoma
}

\author{
Sujit S. Prabhu, Kenneth D. Aldape, Robert F. Gagel, Robert S. Benjamin, \\ Jonathan C. Trent, Ian E. McCutcheon
}

\begin{abstract}
Background: Although the benefits of radiotherapy for pituitary adenomas are welldocumented, post-irradiation sarcomas of the sella are rarely seen, with only 20 cases (mainly of fibrosarcoma) reported in the medical literature. Method: We describe a case of post-irradiation sarcoma five years after surgery followed by external-beam irradiation for an extensive and locally invasive growth hormone-secreting tumor. The patient was subsequently given pegvisomant, an antagonist of growth hormone receptor, to control symptoms of growth hormone excess. Results: The patient underwent transsphenoidal resection of the recurrent tumor, followed by adjuvant chemotherapy. This led to significant relief in the patient's symptoms including radiological evidence of tumor shrinkage, but the tumor regrew when, owing to dose-limiting toxicity, chemotherapy was stopped. Conclusions: Post-irradiation sarcomas of the pituitary are well-recognized but rare. They should be suspected in patients following sellar irradiation who show abrupt onset of new symptoms and appropriate radiological findings, and such tumors may respond to cytotoxic chemotherapy.
\end{abstract}

RÉSUMÉ: Changements sarcomateux dans un adénome pituitaire secrétant de l'hormone de croissance après irradiation de la selle turcique. Introduction: Bien que les bénéfices de la radiothérapie soient bien documentés dans le traitement des adénomes pituitaires, les sarcomes de la selle turcique postirradiation sont rares, seulement 20 cas ayant été rapportés dans la littérature médicale, surtout des fibrosarcomes. Méthodes: Nous décrivons un cas de sarcome post-irradiation cinq ans après une chirurgie suivie d'irradiation pour traiter une tumeur extensive avec envahissement local secrétant de l'hormone de croissance. Le patient a reçu par la suite du pegvisomant, un antagoniste des récepteurs de l'hormone de croissance, pour contrôler les symptômes causés par un excès d'hormone de croissance. Résultats: Le patient a subi une résection transsphénoïdale de la récidive tumorale suivie par une chimiothérapie adjuvante. Les symptômes du patient ont considérablement diminué et on a observé une régression de la tumeur. Cependant il y a eu récidive de la tumeur quand la chimiothérapie a dû être arrêtée à cause de sa toxicité. Conclusions: Les sarcomes de l'hypophyse après irradiation sont bien connus mais rares. On doit soupçonner leur présence chez les patients qui ont subi une irradiation de la selle turcique et qui présentent subitement de nouveaux symptômes et des signes radiologiques appropriés. Ces tumeurs peuvent répondre à la chimiothérapie cytotoxique.

Can. J. Neurol. Sci. 2003; 30: 378-383

Pituitary adenomas are known to have a propensity to invade surrounding structures despite their benign histological appearance. Aggressive behavior by such tumors, defined by rapid growth, radiological or intraoperative evidence of gross invasion of parasellar structures, and/or histopathological evidence of dural invasion, may preclude complete surgical resection. Radiotherapy has been used to treat both invasive pituitary tumors and incompletely resected or recurrent tumors. Subsequent development of a sellar or parasellar sarcoma is a rare event. ${ }^{1-15}$ In this report we describe a case of sarcomatous change within a locally aggressive growth hormone (GH)secreting adenoma four years after irradiation of the sellar region. The patient also received hormonal treatment with pegvisomant, an inactive analogue of $\mathrm{GH}$ and antagonist of its receptor.

\footnotetext{
From the Departments of Neurosurgery (SP, IM); Pathology (KA); and Sarcoma Oncology (RB, JT); Brain Tumor Center (SP, IM, KA); and the Division of Cancer Medicine (RG); The University of Texas MD Anderson Cancer Center, Houston, Texas 77030 USA.

ReCEIVEd DeCEMBer 23, 2002. ACCEPTED In FINAL FORM APRIL 15, 2003 Reprint requests to: Ian E. McCutcheon, Department of Neurosurgery, The University of Texas M.D. Anderson Cancer Center, 1515 Holcombe Boulevard, Box 442, Houston, Texas 77030 USA
} 


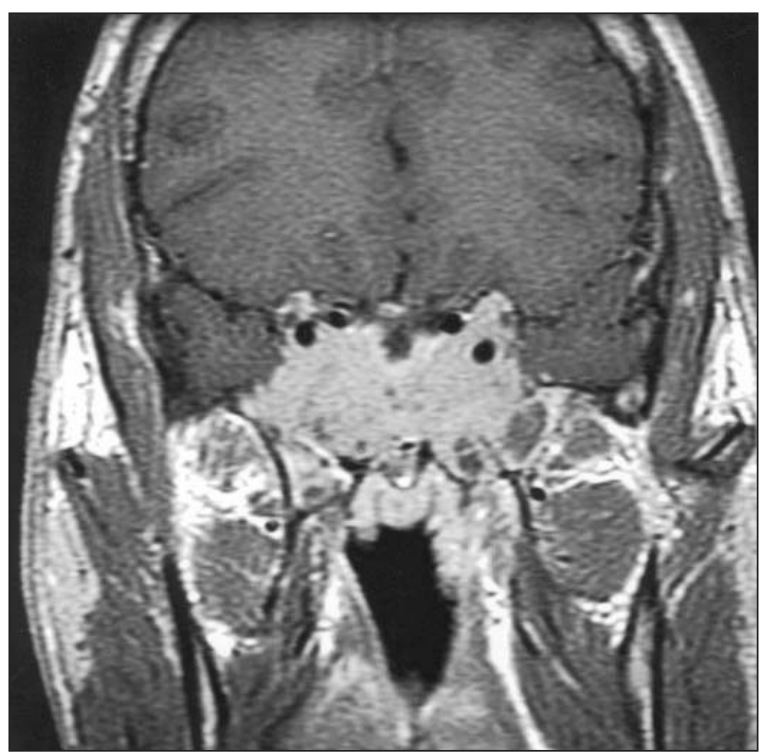

Figure 1: Magnetic resonance image (coronal, T1-weighted, post-contrast) showing a pituitary macroadenoma in the sella and the suprasellar region with involvement of both cavernous sinuses and extensive destruction of the skull base. Tumor also extends into and beyond each foramen ovale.

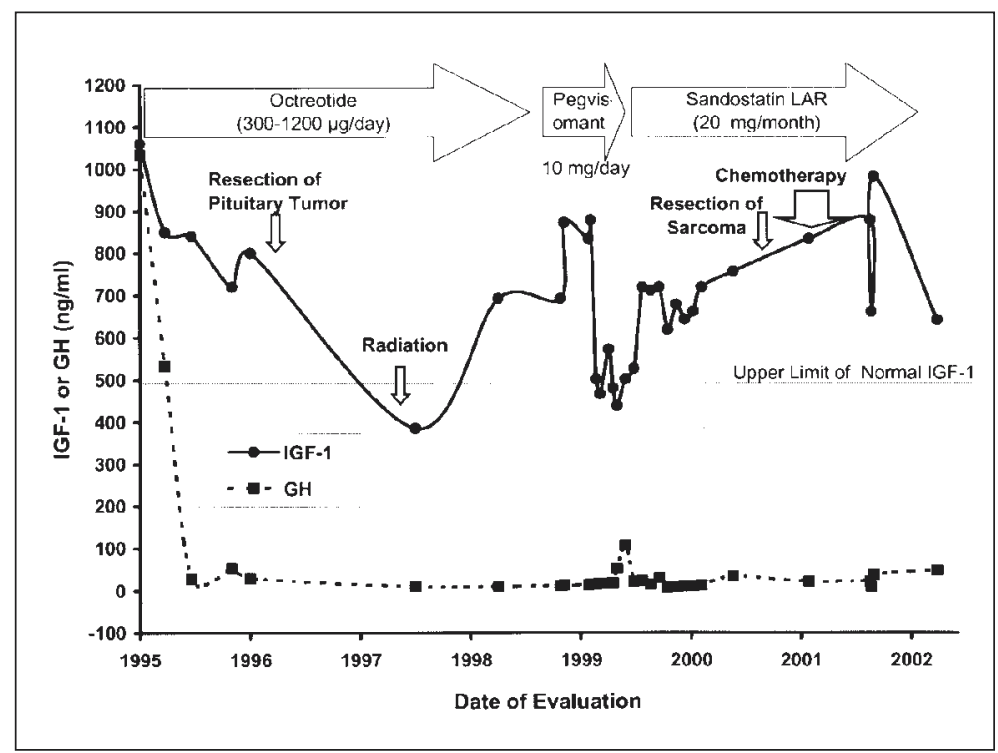

Figure 2: GH and IGF-I levels following initial presentation. Initial therapy with octreotide resulted in a rapid reduction in GH but not normalization. IGF-I also diminished but did not normalize except for a brief period following radiation therapy. Treatment with pegvisomant normalized IGF-I levels with significant improvement in clinical features of acromegaly for the duration of treatment. When that drug became unavailable, the patient was started on Sandostatin LAR; however, IGF-I levels were never completely normalized following discontinuation of pegvisomant.

\section{Clinical History}

The patient's symptoms began at age 11 when he began to grow faster than his identical twin brother. Over the next several years he gained substantially in height. In 1995 at age 20, he was 6 feet 8 inches tall compared to his twin who was 5 feet 10 inches tall. On presentation at that time, he had the classical features of acromegaly with a broad forehead and nose, prominent chin and brow, and large hands and feet. He denied any visual symptoms. His initial magnetic resonance imaging (MRI) showed a large sellar and suprasellar enhancing mass with involvement of both cavernous sinuses, with invasion of the right foramen ovale, and extension into the infratemporal fossa (Figure 1). His serum GH level was $1033 \mathrm{ng} / \mathrm{mL}$ (normal, < $2.3 \mathrm{ng} / \mathrm{mL}$ ). After three weeks of treatment with somatostatin analogue (octreotide), the GH level had fallen to $126 \mathrm{ng} / \mathrm{mL}$. The level of insulin-like growth factor I (IGF-I) fell from $9060 \mathrm{ng} / \mathrm{mL}$ (normal, 114-492 ng/mL) before treatment to $850 \mathrm{ng} / \mathrm{mL}$ during the same interval. Repeat MRI six months after starting octreotide showed a $20 \%$ reduction in tumor size. One year after the clinical diagnosis was made and medical treatment initiated, the patient underwent a right transfacial transmaxillary approach to the sella, sphenoid sinus, and infratemporal fossa with a substantial but subtotal removal of tumor. Although a full panel of anti-hormonal primary antibodies was used, this tumor was positive only for GH. Prior to surgery, his levels of GH $(54 \mathrm{ng} / \mathrm{mL})$ and IGF-I $(720 \mathrm{ng} / \mathrm{mL})$ were both elevated although lower than at the onset of octreotide therapy. He made a good postoperative recovery and his IGF-I levels decreased further, to $250 \mathrm{ng} / \mathrm{mL}$. He continued on octreotide postoperatively.

Because of the residual mass and the aggressive nature of the tumor, he next underwent radiation treatment to a field covering the sphenoid sinus, clivus, both cavernous sinuses, both posterior maxillary sinuses, and the floor of each middle fossa to the foramen ovale, with a $1-\mathrm{cm}$ margin. A total of $50 \mathrm{~Gy}$ was given at $2 \mathrm{~Gy}$ fractions over five weeks in late 1996 using lateral opposing portals with high-energy photons. Prior to radiotherapy his GH levels had risen again to $>1000 \mathrm{ng} / \mathrm{mL}$. During this time, his thyroid function tests and testosterone levels were low and the patient was started on supplemental thyrotropin and testosterone.

Because of persistent clinical symptoms of acromegaly, the patient was taken off octreotide and started on pegvisomant three years after his first operation. His symptoms and clinical features of acromegaly improved thereafter, but his GH levels never normalized (Figure 2). He stopped taking pegvisomant a year later after supplies of this experimental drug ran short, and resumed octreotide injections.

Five years after completing radiotherapy, the patient presented with blurred vision and worsening headaches. On examination he still had the stigmata of acromegaly along with a new partial left abducens palsy. Magnetic resonance imaging showed tumor regrowth mainly within the sella and suprasellar region and infiltrating the left cavernous sinus (Figure 3). He underwent a transsphenoidal resection of this recurrent tumor in November 2001. The tumor was much firmer than the soft tumor removed during his first surgery, was grossly invasive through dura, and was excised with some difficulty from the sella and from the suprasellar cistern.

After surgery the patient completed five cycles of treatment with adriamycin and ifosfamide over seven months. His symptoms markedly improved and follow-up MRI has shown a significant reduction in tumor size (Figure 4). However, dose-limiting toxicity from the chemotherapy forced its cessation and the tumor then grew into the adjacent brainstem, leading to the patient's demise 11 months after diagnosis of the sarcoma. 

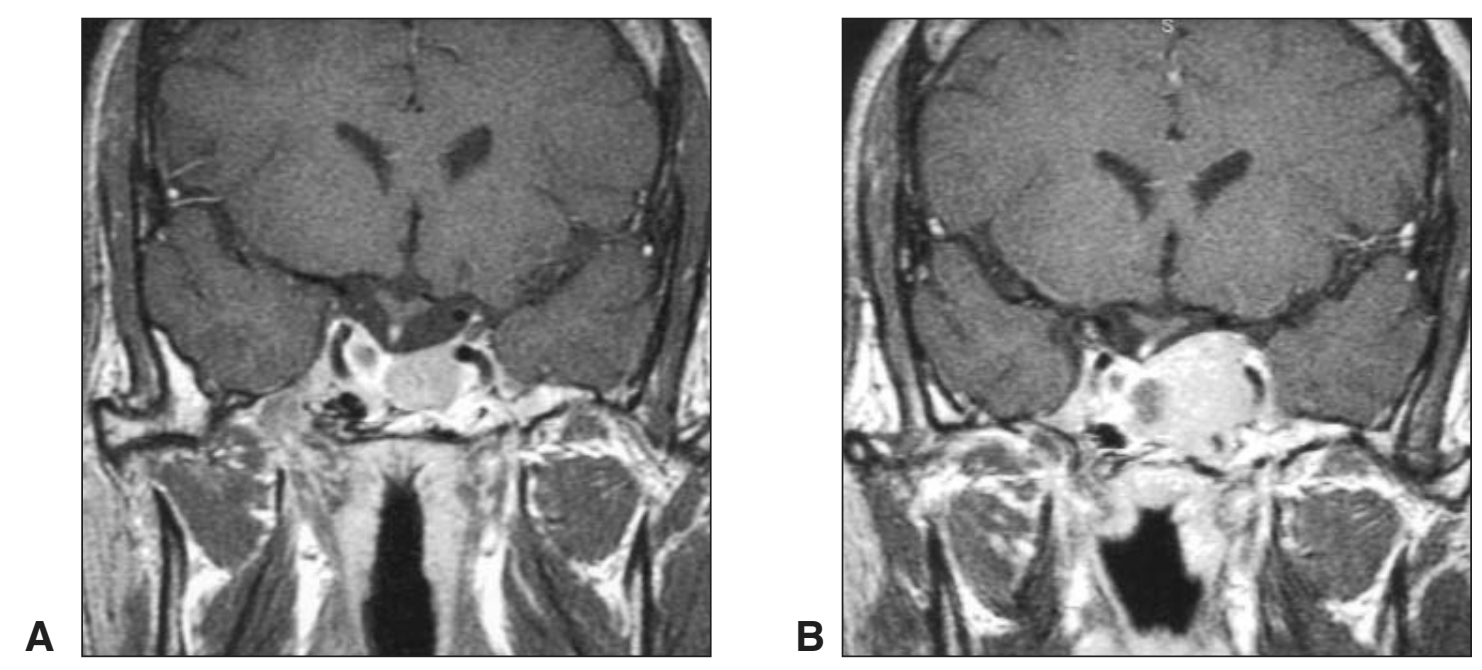

Figure 3: MRI (coronal, T1-weighted, post-contrast) showing (A) the pituitary adenoma significantly smaller following surgery, radiotherapy, and treatment with octreotide and pegvisomant. At this point the tumor had been stable for five years, ever since the conclusion of radiotherapy. (B) Two months later there was significant enlargement of the mass, necessitating transsphenoidal resection of the tumor.

\section{Materials AND METHODS}

Tumor specimens were fixed in $10 \%$ neutral buffered formalin followed by paraffin embedding and sectioning for H\&E staining. Immunohistochemistry was performed using commercially available anti-human antibodies for growth hormone (Zymed), chromogranin (Zymed), vimentin (clone V91, Dako), smooth muscle actin (clone 1A4, Sigma), desmin (clone D33, Dako), CD34 (clone MY10, Becton-Dickinson), and S-100 (rabbit polyclonal 15E2E2, Ventana Labs). Staining for the IGF-I receptor was performed using a rabbit polyclonal antibody directed towards the beta subunit (Santa Cruz Biotechnology, Santa Cruz, CA). Following antigen retrieval (microwaving in citrate buffer) this primary antibody was used at a dilution of 1:200. Appropriate HRP-conjugated secondary antibodies (Vector Labs) were applied according the manufacturer's instructions and a diaminobenzidine substrate was used as a chromagen.

\section{RESULTS}

Histology of the patient's initial lesion revealed a typical pituitary adenoma, containing cells with uniform round nuclei and "salt-and-pepper" chromatin arranged in a trabecular pattern (Figure 5A). Immunohistochemistry for GH revealed positivity in the cytoplasm of most tumor cells (Figure 5B). In contrast, the specimen from the patient's second procedure showed a biphasic tumor, with a predominant spindle cell component consistent with sarcoma. The spindle cells demonstrated signficant nuclear atypia and a mitotic count of 22 per 10 high power fields (400x), features diagnostic of high-grade sarcoma. Islands of neuroendocrine cells with features similar to the patient's original lesion were also identified (Figure 5C). Reticulin and GH staining were performed on adjacent sections and showed positive reticulin staining in only the spindled areas (Figure 5D), and positive GH staining in only the neuroendocrine tumor cells
(Figure 5E). A pattern similar to the GH staining was seen using antibody against chromogranin (not shown). In order to characterize the sarcomatous component, staining for vimentin, smooth muscle actin, desmin, CD34, and S-100 was performed, revealing positivity only for vimentin. The overall histological appearance and staining profile were considered most consistent with fibrosarcoma. In addition, strong cytoplasmic staining within sarcoma cells was demonstrated for the IGF-I receptor (Figure 5F).

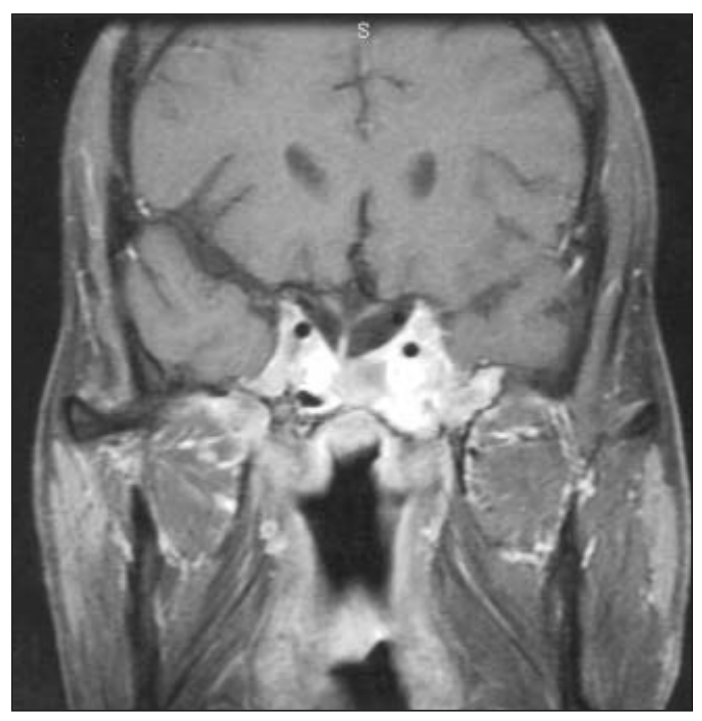

Figure 4: MRI (coronal, T1-weighted, post-contrast) showing significant reduction in tumor size following surgery and subsequent cytotoxic chemotherapy with adriamycin and ifosfamide. 


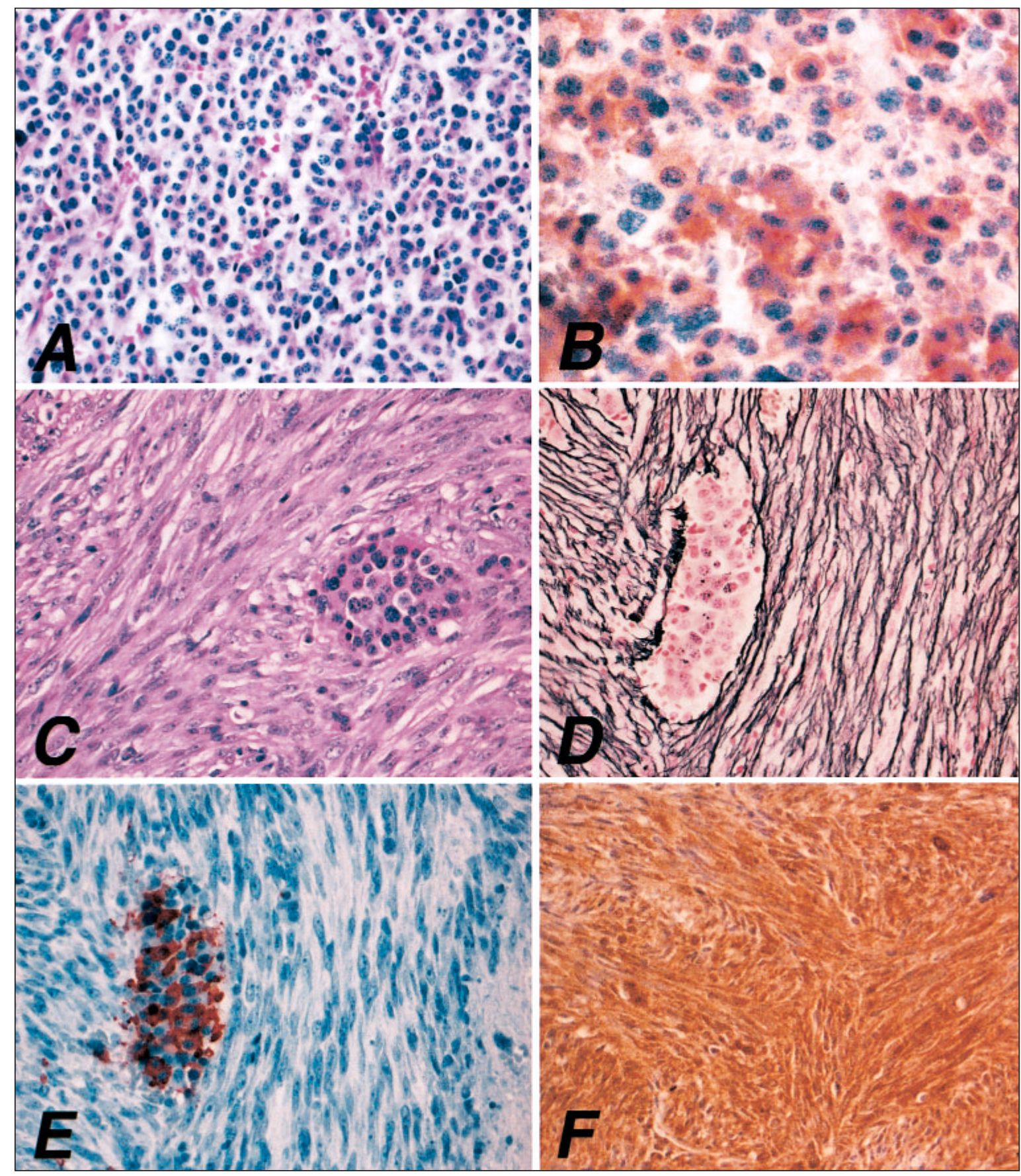

Figure 5: Histology and immunohistochemistry of pituitary lesion. (A) Representative area of initial pituitary adenoma with a benign appearance (hematoxylin and eosin, X200). (B) Immunohistochemistry of the original tumor using a specific anti-GH antibody (X400). (C) Representative section of patient's second tumor showing spindle cells consistent with undifferentiated sarcoma (X200). Staining of the same area of tumor from adjacent sections (X400) showing (D) reticulin and (E) GH. Staining for $(F)$ IGF-I receptor (X400) reveals positive cytoplasmic staining in tumor cells and suggests interaction between the patient's acromegaly and growth of the sarcoma. 


\section{DiscuSSION}

Postsurgical treatments for persistent acromegaly include radiotherapy, dopamine agonists (bromocriptine and cabergoline), and somatostatin analogues (octreotide, longacting octreotide, and lanreotide). More recently pegvisomant, a growth hormone receptor antagonist, has also been used in clinical trials to lower significantly circulating levels of IGF-I, the principal mediator of $\mathrm{GH}$ action. ${ }^{16-18}$ The patient reported here was exposed to irradiation and to both octreotide and pegvisomant. As neither of those drugs is known to stimulate malignant transformation, radiotherapy probably induced this fibrosarcoma.

Although spontaneous sarcomas of the parasellar region are occasionally seen including cases of osteogenic sarcoma, ${ }^{19}$ alveolar soft-part sarcoma, ${ }^{20}$ rhabdomyosarcoma, ${ }^{21}$ and chondrosarcoma, ${ }^{22}$ radiation-induced sarcomas are rare within the sella. Terry, et al ${ }^{13}$ were the first to document the occurrence of fibrosarcoma after radiotherapy for pituitary adenoma. Since then 20 cases of fibrosarcoma of the pituitary fossa have been described following irradiation of pre-existing pituitary adenomas. ${ }^{1-15}$ Although $60 \%$ have arisen from clinically nonfunctional adenomas, immunohistochemical analysis is lacking in most of these cases. Another 30\% have been reported in patients with clinical acromegaly but only one case other than ours has been shown to stain positive for GH. ${ }^{2}$ Two fibrosarcomas have also been described which occurred spontaneously in the sella, ${ }^{23,24}$ and another after treatment of a prolactinoma with bromocriptine with no history of sellar irradiation. $^{25}$

The time from onset of symptoms to the diagnosis of postirradiation sarcoma varies from two to 20 years. ${ }^{11,26}$ Several types of radiotherapy including orthovoltage radiation and more recently cobalt-60, betatron, linear accelerator therapy, and heavy particle cyclotron radiotherapy have been associated with the development of fibrosarcomas. ${ }^{2,3}$ The sarcomas described are mostly of the spindle cell variety but may show mixed patterns of differentiation: recently an osteosarcoma of the pituitary was described in a pre-existing fibrosarcoma. ${ }^{4}$ Single-fraction stereotactic delivery of doses up to 35 Gy has recently been used to treat newly diagnosed and residual pituitary tumors, ${ }^{27}$ and at least one case of sarcoma following stereotactic radiotherapy (in a vestibular schwannoma) has been reported. ${ }^{28}$ However, longterm follow-up of these patients is lacking and the true incidence of late-onset sarcomas cannot yet be stated with that modality.

The cellular origin of this relatively undifferentiated sarcoma cannot be determined with certainty. Although osteosarcoma has been induced in parasellar bone, ${ }^{29}$ this tumor's identity as a fibrosarcoma might suggest that it arose from the dura lining the sella, or from the pituitary gland itself. However, the interlacing of the sarcomatous and adenomatous components implies that the sarcomatous component was derived from the pre-existing pituitary adenoma. Sarcomatous change has also been reported in other irradiated intracranial tumors, including gliomas. ${ }^{30}$

This patient's sarcoma was strongly positive for the IGF-I receptor (Figure $5 \mathrm{~F}$ ). If these receptors are functional, then his ongoing GH and/or IGF-I excess may have encouraged the growth of the malignancy. Others have reported sarcoma development in acromegalic patients. Wright's ${ }^{31}$ series of 194 patients with acromegaly contains one with a co-existing fibrosarcoma, as does Nabarro's ${ }^{32}$ series of 265 patients with GH excess. In addition, Barzilay et $\mathrm{al}^{33}$ reported one patient with an unclassified sarcoma among 87 with acromegaly. Thus, the incidence of sarcoma among these 537 cases of acromegaly was $0.56 \%$, a relatively high number that supports an association between sarcomagenesis and excess circulating GH and/or IGFI.

IGF-I induces cell proliferation in many (but not all) sarcoma cell lines. ${ }^{34}$ When bound by the appropriate ligand, the IGF-I receptor activates ERK 1 and 2, STATs, and Akt, which govern the phenotypic characteristics of both normal and neoplastic cells. ${ }^{35}$ It also activates the downstream molecule p38, which rescues tumor cells from otherwise lethal DNA damage by modifying degradation of p53. ${ }^{36}$ This allows damaged cells to continue to proliferate, and may thereby promote malignant transformation as seen in our case.

Following the diagnosis of fibrosarcoma the patient was started on ifosfamide and adriamycin with good results. There was, at first, symptomatic improvement along with reduction in tumor size (Figure 3A). However, after five cycles the patient developed dose-limiting toxicity and medical therapy had to be stopped. Although adjuvant chemotherapy is palliative rather than curative, it has occasionally been successful in treating radiation-induced sarcomas and offers an additional avenue for managing this difficult problem. ${ }^{26}$ However, the positive effects of such treatment may diminish in the face of ongoing IGF-I excess, a limitation that might be overcome by administering pegvisomant to such patients while they continue a chemotherapeutic regimen.

This case highlights the possibility of developing a sarcoma after irradiation of a pituitary adenoma. As this event is disproportionately reported in acromegalic patients and, as the patient reported here had a sarcoma positive for IGF-I receptor, we speculate that overactivity of the GH/IGF-I axis encourages such sarcoma formation.

\section{REFERENCES}

1. Ahmad K, Fayos JV. Pituitary fibrosarcoma secondary to radiation therapy. Cancer 1978; 42: 107-110.

2. Ahmed M, Kanaan I, Rifai A, Tulbah A, Ghannam N. An unusual treatment-related complication in a patient with growth hormonesecreting pituitary tumor. J Clin Endocrinol Metab 1997; 82: 2816-2820.

3. Coppeto JR, Roberts M. Fibrosarcoma after proton-beam pituitary ablation. Arch Neurol 1979; 36: 380-381.

4. Gnanalingham KK, Chakraborty A, Galloway M, Revesz T, Powell M. Osteosarcoma and fibrosarcoma caused by postoperative radiotherapy for a pituitary adenoma. Case report. J Neurosurg 2002; 96: 960-963.

5. Goldberg MB, Sheline GE, Malamud N. Malignant intracranial neoplasms following radiation therapy for acromegaly. Radiology 1962; 80: 465-470.

6. Greenhouse AH. Pituitary sarcoma. A possible consequence of radiation. J Am Med Assoc 1960; 190: 269-273.

7. Martin WH, Cail WS, Morris JL, Constable WC. Fibrosarcoma after high-energy radiation therapy for pituitary adenoma. AJR Am J Roentgenol 1980; 135: 1087-1090.

8. Nagatani M, Ikeda T, Otsuki H, et al. [Sellar fibrosarcoma following radiotherapy for prolactinoma]. No Shinkei Geka 1984; 12: 339346.

9. Pieterse S, Dinning TA, Blumbergs PC. Postirradiation sarcomatous transformation of a pituitary adenoma: a combined pituitary tumor. Case report. J Neurosurg 1982; 56: 283-286. 
10. Powell HC, Marshall LF, Ignelzi RJ. Postirradiation pituitary sarcoma. Acta Neuropathol (Berl) 1977; 39: 165-167.

11. Shi T, Farrell MA, Kaufmann JC. Fibrosarcoma complicating irradiated pituitary adenoma. Surg Neurol 1984; 22: 277-284.

12. Shin $\mathrm{H}, \mathrm{Namba} H$, Ishige $\mathrm{N}$, et al. [Pituitary fibrosarcoma secondary to radiation therapy for the treatment of chromophobe adenoma]. No Shinkei Geka 1980; 8: 605-614.

13. Terry RD, Hyams VJ, Davidoff LM. Combined nonmetastasizing fibrosarcoma and chromophobe tumor of the pituitary. Cancer 1959; 12: 791-798.

14. Waltz TA, Brownell B. Sarcoma: a possible late result of effective radiation therapy for pituitary adenoma. Report of two cases. $\mathrm{J}$ Neurosurg 1966; 24: 901-907.

15. Wheelock MC. Eosinophilic adenoma of the pituitary with sarcomatous changes. Cancer Sem 1963; 3: 77-80.

16. Drake WM, Parkinson C, Besser GM, Trainer PJ. Clinical use of a growth hormone receptor antagonist in the treatment of acromegaly. Trends Endocrinol Metab 2001; 12: 408-413.

17. Trainer PJ, Drake WM, Katznelson L, et al. Treatment of acromegaly with the growth hormone-receptor antagonist pegvisomant. N Engl J Med 2000; 342: 1171-1177.

18. Utiger RD. Treatment of acromegaly. N Engl J Med 2000; 342: 1210-1211.

19. Reichenthal E, Cohen ML, Manor CR, et al. Primary osteogenic sarcoma of the sellar region. Case report. J Neurosurg 1981; 55: 299-302.

20. Bots GT, Tijssen CC, Wijnalda D, Teepen JL. Alveolar soft part sarcoma of the pituitary gland with secondary involvement of the right cerebral ventricle. Br J Neurosurg 1988; 2: 101-107.

21. Jalalah S, Kovacs K, Horvath E, et al. Rhabdomyosarcoma in the region of the sella turcica. Acta Neurochir (Wien) 1987; 88: 142146.

22. Allan CA, Kaltsas G, Evanson J, et al. Pituitary chondrosarcoma: an unusual cause of a sellar mass presenting as a pituitary adenoma. J Clin Endocrinol Metab 2001; 86: 386-391.

23. Lopes MB, Lanzino G, Cloft HJ, et al. Primary fibrosarcoma of the sella unrelated to previous radiation therapy. Mod Pathol 1998; 11: $579-584$

24. Tachibana E, Saito K, Wakabayashi T, et al. Sarcomatous transformation of a prolactinoma associated with development of a fatal internal carotid artery pseudoaneurysm--case report. Neurol Med Chir (Tokyo) 2000; 40: 427-431.

25. Nagasaka T, Nakashima N, Furui A, Wakayabashi T, Yoshida J. Sarcomatous transformation of pituitary adenoma after bromocriptine therapy. Hum Pathol 1998; 29: 190-193.

26. Patel SR. Radiation-induced sarcoma. Curr Treat Options Oncol 2000; 1: 258-261.

27. Thoren M, Hoybye C, Grenback E, et al. The role of gamma knife radiosurgery in the management of pituitary adenomas. J NeuroOncol 2001; 54: 197-203.

28. Thomsen J, Mirz F, Wetke R, et al. Intracranial sarcoma in a patient with neurofibromatosis type 2 treated with gamma knife radiosurgery for vestibular schwannoma. Am J Otol 2000; 21: 364-370.

29. Amine ARC, Sugar O. Suprasellar osteogenic sarcoma following radiation for pituitary adenoma. J Neurosurg 1976; 44: 88-90.

30. Lach M, Wallace CJ, Krcek J, Curry B. Radiation-associated gliosarcoma. Can Assoc Radiol J 1996; 47: 209-212.

31. Wright AD, Hill DM, Lowy C, Fraser TR. Mortality in acromegaly. Q J Med 1970; 39: 1-16.

32. Nabarro JD. Acromegaly. Clin Endocrinol 1987; 26: 481-512.

33. Barzilay J, Heatley GJ, Cushing GW. Benign and malignant tumors in patients with acromegaly. Arch Int Med 1991; 151: 1629-1632.

34. Remmelink M, Decaestecker C, Darro F, et al. The in vitro influence of eight hormones and growth factors on the proliferation of eight sarcoma cell lines. J Cancer Res Clin Oncol 1998; 124: 155-164.

35. Schlessinger J. Cell signaling by receptor tyrosine kinases. Cell 2000; 103: 211-225.

36. Heron-Milhavet L, LeRoith D. Insulin-like growth factor I induces MDM2-dependent degradation of p53 via the p38 MAPK pathway in response to DNA damage. J Biol Chem 2002; 277: $15600-15606$. 